\title{
THE FIRST WORKERLESS PARASITE IN THE ANT GENUS FORMICA (HYMENOPTERA: FOR MICIDAE)
}

\author{
BY EDWARD O. WILSON \\ Museum of Comparative Zoology, Harvard University, \\ Cambridge, Massachusetts 02138 U.S.A.
}

Abstract. Formica talbotae Wilson, a member of the microgina group and the first proven workerless parasite in Formica, is described here. The species is known from Michigan, Iowa, and North Dakota. The discovery of talbotae completes the inferred evolutionary progression within Formica from independent existence through temporary parasitism to permanent, workerless parasitism.

During her exhaustive survey of the ant fauna of the Edwin S. George Reserve of Michigan, an effort previously unparalleled in North America, Mary Talbot has uncovered a surprising number of rare and undescribed species. One of the most significant is the species to be described below, a member of the Formica microgyna group which to the best of my knowledge is the first adequately documented example of a workerless parasite in this large Holarctic genus.

\section{Formica talbotae Wilson, new species}

Diagnosis (queen). A small species even for the microgyna group, characterized further by the following combination of traits: subquadrate head; smoothly rounded anterior clypeal border; thick petiolar node with relatively thick, rounded crest; short $(0.05-0.08 \mathrm{~mm})$, dense standing pilosity over all of body and appendages, including scape; many of the hairs on the thoracic dorsum, propodeum, petiole, and fore coxae spatulate. So far as known, talbotae is exclusively a workerless parasite of Formica obscuripes Forel.

Relationships. During the study I examined specimens of all of the microgyna group species for which sexual forms are known. Most of those known from workers solely were also examined, but are in any case considered probably distinct on the basis of the possession of a worker caste alone. The closest species is $F$. dirksi Wing, which differs in the queen caste by its slightly larger size; much longer, less frequently spatulate pilosity; and more rounded head shape. F. spatulata Buren is also close but its queen 
is distinguished by a much shorter pilosity; rounded, tapering head shape; much sparser pilosity; and the certain existence of a worker caste.

Holotype queen. Head width, across and including the compound eyes, $1.12 \mathrm{~mm}$; head length, exclusive of mandibles, 1.21 $\mathrm{mm}$; scape length $1.17 \mathrm{~mm}$; total body length approximately $4.8 \mathrm{~mm}$. Most of the diagnostic features have been illustrated in Figure 1. Body medium brown, with sides of pronotum light brown; appendages mostly light, almost light yellowish brown.

Edwin S. George Reserve, Livingston Co., Michigan; 16 August 1971; collected by Mary Talbot, series no. 71-45, in a nest of Formica obscuripes.

Other series. Fifteen paratype queens from the holotype nest series varied in head width $1.12-1.18 \mathrm{~mm}$ (mean $1.15 \mathrm{~mm}$ ). Queens in five additional nest series from the type locality (collection dates: 25 June 1969, 29 June 1970, 17 September 1970, 18 September 1970, 29 July 1974) were closely similar to the holotype nest series in size and other characteristics. All were collected in nests of F. obscuripes (see Talbot, 1977).

An additional series of $F$. talbotae queens was examined from Lakeside Laboratory, Milford, Iowa; they had been taken from a nest of Formica obscuripes by R. L. King (accession no. 485, 13 July 1952). These are closely similar in all traits to the holotype nest series; for example, the head width of 8 specimens was 1.12 $1.17 \mathrm{~mm}$ (mean $1.15 \mathrm{~mm}$ ). A third series from the University of North Dakota Biological Area, Grand Forks Co., North Dakota (P. B. Kannowski leg., 3 August 1971) was assigned to talbotae. These queens differed from the Michigan series in having somewhat denser pilosity and being slightly larger (head width of 5 queens was $1.18-1.19 \mathrm{~mm}$ ). They were also collected in a nest of $F$. obscuripes.

Males. Males in the holotype nest series and other collections from the E. S. George Reserve are distinguished from males of other microgyna group species by pilosity traits paralleling those of the queens: the hairs are short $(0.05-0.08 \mathrm{~mm})$ and dense on both the body and appendages, with many on the occiput, mesonotum, and propodeum blunt to spatulate. Head width of 10 individuals in the holotype nest series was 1.12-1.29 mm (mean $1.22 \mathrm{~mm}$ ). 
Type deposition. The holotype and many paratypes are in the Museum of Comparative Zoology, Harvard University, while paratypes from the holotype nest series have been deposited in the U.S. National Museum and Los Angeles County Natural History Museum.

Discussion. In their recent review Letendre and Huot (1972) note that the $F$. microgyna group is exclusively Nearctic, its various species occupying a total range from central Mexico north to British Columbia and east to Quebec and the Carolinas. As W. M. Wheeler (1904) first showed in the case of F. difficilis, the tiny queens enter the nests of other species of Formica. These host colonies either lack queens of their own at the outset or else lose them subsequently, by means still unknown. The offspring of
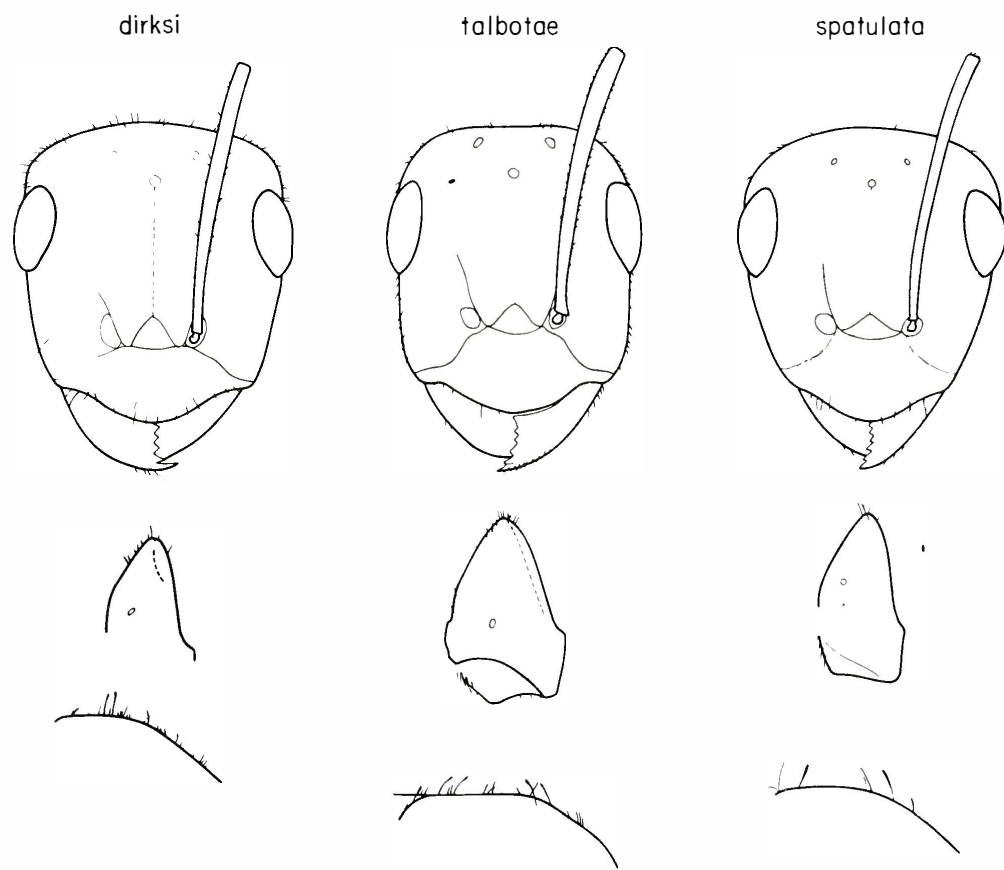

Figure 1. Frontal view of head and side views of basal propodeal face and petiolar scale of queens of Formica dirksi Wing (holotype), F. talbotae Wilson (holotype), and F. spatulata Buren (paratype). 
the parasite queen are ordinary in size and behavior in comparison with other Formica, and they gradually supplant the host workers until a pure, newly independent parasite colony comes into existence. In short, most of the species of the microgyna group appear to be temporary social parasites.

Wing (1949) described $F$. dirksi from a single queen found in the nest of a Formica fusca (form "subaenescens") colony in northern Maine. Because of the absence of microgyna-group workers, he suggested that it might be a workerless social parasite. This may well be true, especially in view of the similarity now revealed between dirksi and talbotae. However, talbotae is the first well documented example of a workerless parasite in the genus. Both W. F. Buren and I have searched through extensive series of $F$. obscuripes containing queens and males of $F$. talbotae without finding a single microgyna-group worker, nor were such workers found in the North Dakota mixed series. In one thorough survey of a mixed nest in Michigan, Talbot (1977) found only workers of $F$. obscuripes. It is reasonable to conclude, therefore, that either talbotae is entirely workerless or else its worker caste is so scarce as to restrict it to a state of permanent social parasitism.

Thus the significance of $F$. talbotae is that it completes the evolutionary sequence within Formica from complete independence through temporary social parasitism to permanent social parasitism, with an apparent total loss of the worker caste. It is worth noting also that so far as known other microgyna-group species, including dirksi, parasitize members of the fusca, neogagates, and pallidefulva groups of Formica, whereas talbotae is associated with a member of the rufa group. This difference may prove significant with reference to the extreme state of social parasitism achieved by talbotae, although the data are still too few to establish host specificity with any degree of confidence.

\section{ACKNOWLEDGMENTS}

I wish to thank Mary Talbot, William F. Buren, and Paul B. Kannowski for supplying me with the specimens described here, Akey C. F. Hung for providing data on the Iowa series, and David $\mathrm{R}$. Smith for the loan of the unique holotype of $F$. dirksi. The study has been supported by National Science Foundation Grant no. BNS73-00889. 


\section{Literature Cited}

Buren, W. F.

1942. New ants from Minnesota, Iowa and Wisconsin. Iowa State College Journal of Science 16: 399-408.

Letendre, M. AND L. Huot

1972. Considérations préliminaires en vue de la revisıon taxonomique des fourmis du groupe microgyna, genre Formica (Hymenoptera: Formicidae). Ann. Soc. Ent. Québec 17: 117-132.

TALBOI, M.

1977. The natural history of the workerless ant parasite, Formica talbotae. Psyche 83: 282-288.

WheEler, W. M.

1904. A new type of social parasitism among ants. Bull. Amer. Mus. Nat. Hist. 20: $347-375$.

WING, W. M.

1949. A new Formica from northern Maine, with a description of its supposed type of social parasitism (Hymenoptera: Formicidae). Canadian Entomologist 81: 13-17. 


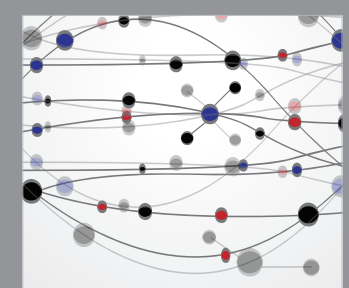

The Scientific World Journal
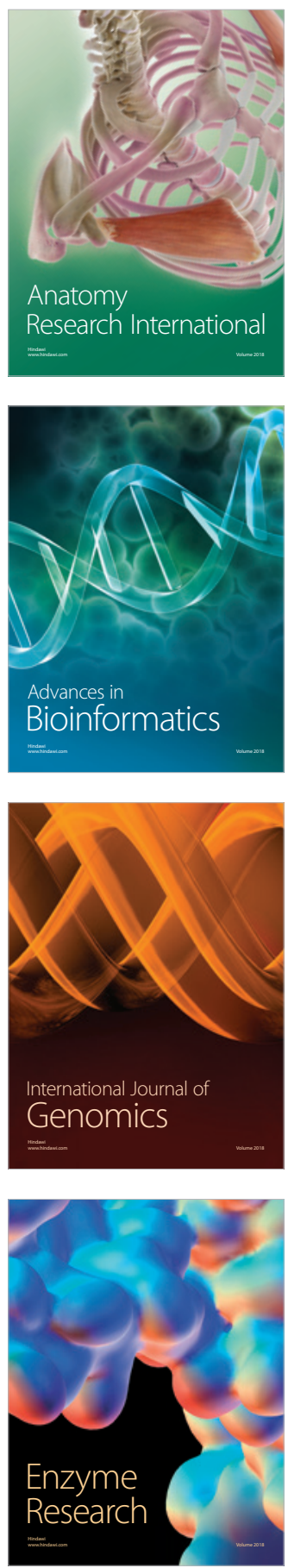
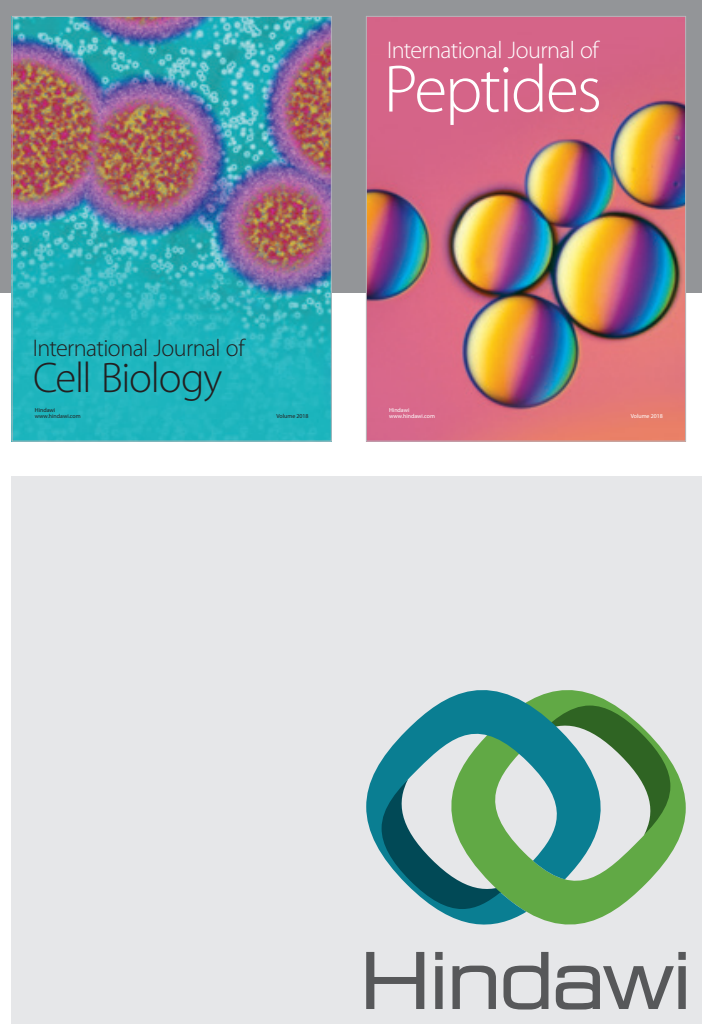

Submit your manuscripts at

www.hindawi.com
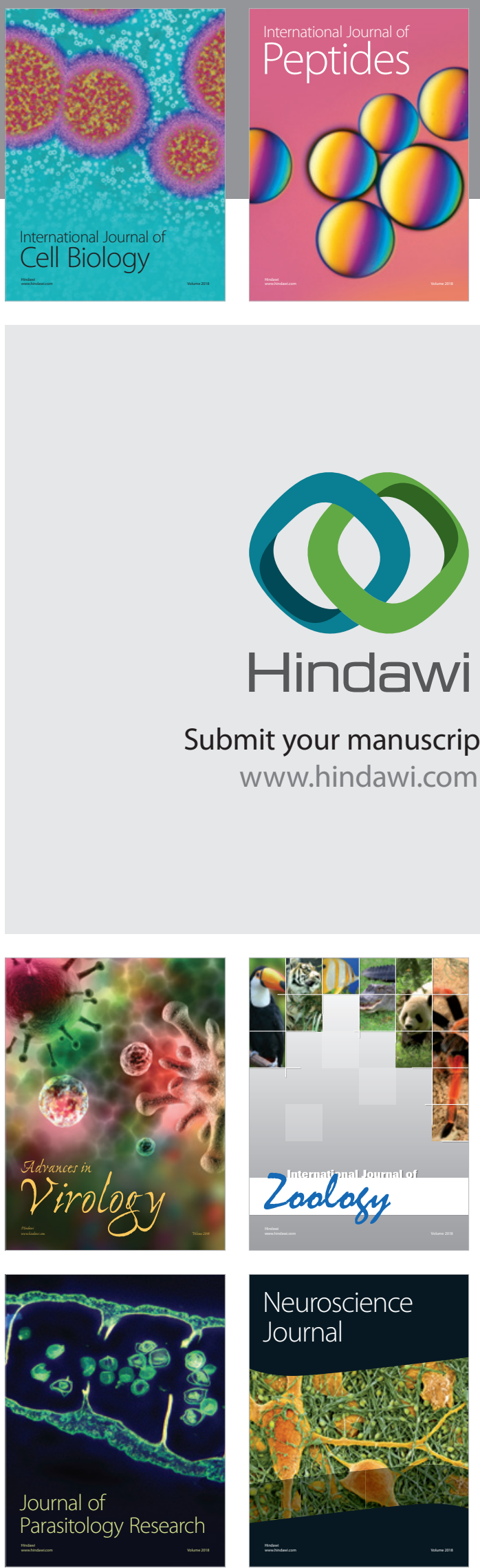
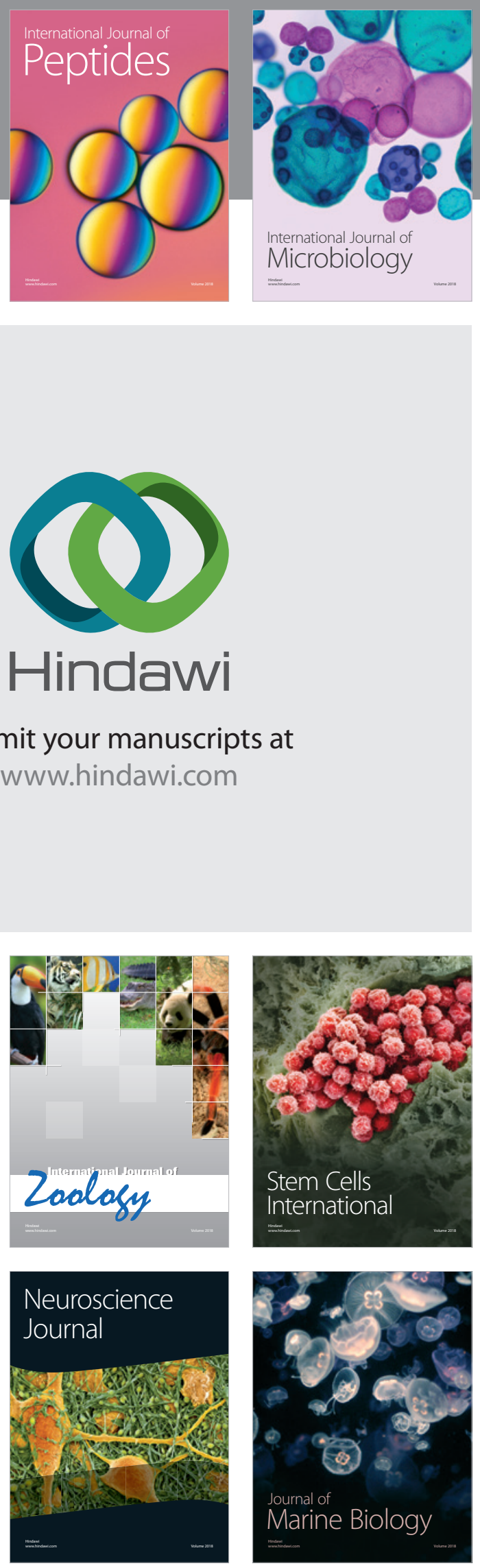
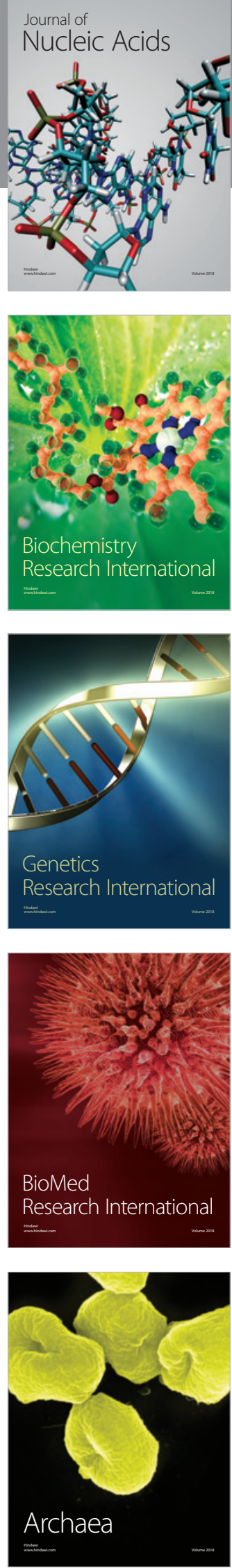